\title{
The effect of intervals between surveys on the estimation of incidence rates of leprosy
}

\author{
K JESUDASAN*, D BRADLEY $\dagger$, P G SMITH† \\ \& M CHRISTIAN* \\ * Department of Epidemiology and Leprosy Control, Schieffelin \\ Leprosy Research and Training Centre, Karigiri, South India; \\ $\dagger$ Ross Institute, London School of Hygiene and Tropical Medicine, \\ London WCIE 7 HT
}

\section{Accepted for publication 16 January 1984}

\begin{abstract}
Summary This paper examines the effect that variation in the interval between successive cross-sectional surveys may have on estimates of the incidence rates of leprosy. The results of the present study showed that when surveys of the contacts of leprosy patients were conducted in consecutive years (gap between surveys of 1 year) the estimated incidence rate of leprosy was $4 \cdot 7$ per 1000 person years of risk. When there was a gap of 3 years between surveys the estimated incidence rate of leprosy was only 1.9 per 1000 person years of risk. Thus when the between-survey interval increased from 1 to 3 years, the estimated incidence rate of leprosy was halved. Similar findings were obtained from the results of prevalence surveys in the general population. The implications of these findings in relation to survey work in leprosy and possible vaccine trials are discussed.
\end{abstract}

\section{Introduction}

There is evidence that a substantial proportion of cases of non-lepromatous leprosy may heal spontaneously without treatment. For example, it has been found ${ }^{9}$ that between 40 and $75 \%$ of early cases of non-lepromatous leprosy healed without any treatment. Similar findings have also been reported. ${ }^{8,} 10$

Thus estimates of the incidence rates of leprosy, based on the results of repeated and linked cross-sectional surveys of a population, are likely to vary according to the length of the interval between successive surveys. If this interval is long, some cases of leprosy will develop and resolve during the interval and thus go undetected. This has been suggested ${ }^{11}$ but no evidence has been presented previously to show that this occurs in population-based studies.

The data presented in this paper were collected as part of the leprosy control programme at the Schieffelin Leprosy Research and Training Centre, 
Gudiyatham Thaluk in South India. The first part of the paper is based on data collected in a sample survey of the general population in Gudiyatham Thaluk, and the second part is based on data collected from repeated surveys of the contacts of leprosy patients.

INCIDENCE RATES OF LEPROSY IN THE GENERAL POPULATION AMONG INDIVIDUALS NOT KNOWN TO BE EXPOSED TO LEPROSY IN THE HOUSEHOLD

It has been estimated ${ }^{12}$ that the annual incidence rate of leprosy in Gudiyatham Thaluk, in individuals not known to be exposed to leprosy in their own household was $0 \cdot 8$ per 1000 . This estimate was based on surveys done $3-5$ years apart.

To examine the influence of the interval between surveys on estimates of the incidence rates of leprosy, a random sample of the population of Gudiyatham Thaluk, not known to be exposed to leprosy in the household, was resurveyed after an interval of 1 year. One centre from each of the 4 sub-divisions of the Thaluk was surveyed in early 1981 . Households in which no cases of leprosy were found in 1981, were resurveyed early in 1982. The incidence rate of leprosy was calculated among them.

\section{Results}

In the 4 centres included in the study, 27,371 individuals were examined in 1981 who showed no evidence of leprosy and who had no known household contact with leprosy. Of these persons, 23,090 (84\%) were re-examined in 1982 after an interval of 1 year. There were 37 new cases of leprosy detected in the population re-examined, giving an annual incidence rate of 1.6 per 1000 persons examined.

The estimated incidence rate of leprosy calculated by Rao et al., ${ }^{12}$ with an interval between surveys of 3-5 years, was $0 \cdot 8$ per 1000 population examined. Thus, increasing the survey interval from 1 to 3 to 5 years, appears to halve the measured incidence rate of leprosy. It should be noted, however, that the first study ${ }^{12}$ was conducted more than 10 years before the present one and, although both were in the same area, it is possible that some of the differences in incidence rates may be due to methodological variations in the survey techniques and some may be due to true changes in the rates of disease.

To investigate further the influence that the interval between surveys has on estimates of the incidence rates of leprosy, data from repeated surveys of the household contacts of leprosy patients in the same area were also analysed.

INCIDENCE RATES OF LEPROSY AMONG HOUSEHOLD CONTACTS OF NON-LEPROMATOUS AND LEPROMATOUS LEPROSY PATIENTS

The data on which this analysis is based were collected as part of a study of the 
risk of leprosy among the household contacts of leprosy patients. Household contacts of registered leprosy patients living in Gudiyatham Thaluk have been surveyed annually, after the first case in the household was identified and registered for treatment. This procedure was adopted as part of the control programme, as previous studies had shown that such contacts had a higher risk of developing leprosy than individuals not exposed to leprosy in the household. During each of the annual contact surveys, however, not all the contacts have been seen, although the surveys are planned to include at least $85 \%$ of the contacts. Individuals may escape examination if they are temporarily absent from the household at the time of a survey. Thus some contacts have been examined every year (between survey gap of 1 year), others after an interval of 2 years (between survey gap of 2 years) and others after an interval of 3 or more years. Estimates of the incidence of leprosy among contacts were made after different between-survey intervals.

For all 'contacts' in the study the 'person years' of follow-up of each individual were divided according to the gaps between examinations. For example, consider the survey data for an individual as illustrated in Figure 1. This

Contact Survey Number (Conducted annually)

$$
\frac{1}{\mathrm{~S}} \frac{2}{\mathrm{~S}} \frac{3}{\mathrm{~S}} \frac{4}{\mathrm{~S}} \frac{5}{\mathrm{~N}} \frac{6}{\mathrm{~S}} \frac{7}{\mathrm{~N}} \frac{8}{\mathrm{~N}} \frac{9}{\mathrm{~S}} \frac{10}{\mathrm{~N}} \frac{11}{\mathrm{~N}} \frac{12}{\mathrm{~S}}
$$

$\mathrm{S}$, examined and found healthy; $\mathrm{N}$, not examined during this survey.

Figure 1

person was 'at risk' of developing leprosy for a total of 12 years but was not seen on the surveys conducted in years $5,7,8,10$ and 11 . The 12 person years at risk were divided as follows: Intersurvey gap of 1 year $=4$ years at risk (between 0 and 1,1 and 2, 2 and 3, 3 and 4); intersurvey gap of 2 years $=2$ years at risk (between 4 and 6 ); and intersurvey gap of 3 years $=6$ years at risk (between 6 and 9, 9 and 12.)

Individuals who were found to have developed leprosy at a survey were classified according to the interval that had elapsed since they were previously seen (and were healthy) (i.e. 1, 2, 3 years, etc). In computing the person years at risk it was assumed that, on average, they developed leprosy half-way through the interval. The numbers of cases of leprosy detected after different inter-survey intervals were divided by the person years at risk associated with each interval (calculated as above) to obtain estimates of leprosy incidence rates after different survey intervals.

\section{Results}

Table 1 summarizes the findings from these analyses. When the interval between 
Table 1. Incidence rates of leprosy among household contacts of leprosy patients according to the between-survey gaps

\begin{tabular}{|c|c|c|c|c|c|c|}
\hline \multirow{2}{*}{$\begin{array}{l}\text { Diagnosis of } \\
\text { index case }\end{array}$} & & \multicolumn{5}{|c|}{ Between survey gap (years) } \\
\hline & & 1 & 2 & 3 & 4 & $5 \dagger$ \\
\hline \multirow{3}{*}{ Non-lepromatous } & Secondary cases & 130 & 24 & 10 & 3 & 3 \\
\hline & $\begin{array}{l}\text { Person years at } \\
\text { risk }\end{array}$ & 30,034 & 7277 & 5788 & 2578 & 2782 \\
\hline & Incidence rate* & $4 \cdot 3$ & $3 \cdot 3$ & $1 \cdot 7$ & $1 \cdot 2$ & $1 \cdot 1$ \\
\hline \multirow{3}{*}{ Lepromatous $\dagger$} & Secondary cases & 44 & 8 & 4 & 1 & 1 \\
\hline & $\begin{array}{l}\text { Person years at } \\
\text { risk }\end{array}$ & 6964 & 1809 & 1751 & 770 & 668 \\
\hline & Incidence rate* & $6 \cdot 3$ & $4 \cdot 4$ & $2 \cdot 3$ & $1 \cdot 3$ & $1 \cdot 3$ \\
\hline \multirow{6}{*}{ Total } & Secondary cases & 174 & 32 & 14 & 4 & 4 \\
\hline & $\begin{array}{l}\text { Person years at } \\
\text { risk }\end{array}$ & 36,998 & 9086 & 7539 & 3348 & 3450 \\
\hline & Incidence rate:* & & & & & \\
\hline & Crude & $4 \cdot 70$ & $3 \cdot 52$ & $1 \cdot 86$ & $1 \cdot 19$ & $1 \cdot 16$ \\
\hline & Adjusted (1) $\ddagger$ & $4 \cdot 66$ & $3 \cdot 63$ & $1 \cdot 88$ & $1 \cdot 19$ & $1 \cdot 15$ \\
\hline & Adjusted (2) $\ddagger$ & $4 \cdot 74$ & $3 \cdot 54$ & $1 \cdot 79$ & $1 \cdot 21$ & $1 \cdot 14$ \\
\hline
\end{tabular}

* per 1000 person years at risk.

$\dagger$ Borderline lepromatous and lepromatous leprosy combined.

\$(1) Rates after standardizing for age and sex differences.

(2) Rates after standardizing for time since diagnosis of index case (standardization by the indirect method using the specific rates for the whole study group as standard).

surveys was 1 year, the estimated incidence rate of leprosy among household contacts was 4.7 per 1000 person years of risk. When there was a gap between surveys of 2 years the estimated incidence rate of leprosy was $3 \cdot 5$; when there was a gap of 3 years the estimated incidence rate of leprosy was 1.9 and when the between-survey gap was 4 years or more the estimated incidence rate of leprosy among household contacts was $1 \cdot 2$ per 1000 person years of risk. Thus when the between-survey gap was increased from 1 to 3 years or 2 to 4 years, the estimated incidence rate of leprosy was reduced by more than half. The decline in the estimated incidence rate with increasing inter-survey gaps is highly significant $\left(\chi^{2}\right.$ $(1$ d.f. trend $)=26 \cdot 6 ; P<0 \cdot 001)$.

It seemed possible that some of the differences shown in Table 1 might be due to variations in the age and sex composition of the groups compared. For example, if adults were more often 'missed' in surveys than children the lower incidence rates associated with longer between-survey gaps might arise because these latter groups comprise a disproportionate number of adults (who have a lower incidence of leprosy than children). To allow for this possibility the person 
years and leprosy cases in each group were classified by age (in 5-year groups up to 54 years and 1 group for older persons) and sex. Incidence rates adjusted for age and sex differences were calculated using the method of indirect standardization (with the age-sex specific rates for all groups combined as the standard). As may be seen in Table 1 this made no material difference to the trend in incidence rates with different between-survey gaps.

It also seemed possible that a spurious correlation might arise if the frequency of 'missed surveys' increased and the incidence rate of leprosy decreased as the time since diagnosis of the index case increased. To take account of this possibility the incidence rates shown in Table 1 were also standardized for the time since the diagnosis of the index case. This again, however, made no material difference to the findings.

\section{Discussion}

The analysis of these data indicates that the more frequently surveys are conducted the higher will be the estimates of incidence rates of leprosy. This is probably because a high proportion of early cases heal spontaneously without any treatment (over $50 \%$ within $2-3$ years). Surveys done infrequently will fail to pick up cases that have evolved and healed spontaneously between 2 surveys.

A consequence of this finding is that cases of leprosy detected when frequent surveys are done are likely to be less severe (i.e. are more likely to resolve spontaneously) than those that will be detected on less frequent examinations. There were only 22 incident cases detected in the group with a between-survey gap of 3 years or more, and this effect could not be demonstrated with the present data.

The apparent decline in incidence rate with increasing intervals between surveys should be strongest for those forms of the disease with the greatest tendency to spontaneous healing. Thus it might be expected that the effect would be strong for tuberculoid forms of leprosy but not for lepromatous forms. Unfortunately, we were unable to test this in the present study as only 8 of the secondary cases detected were of the lepromatous form.

In interpreting the results of this study the possibility of bias in the findings must be considered. Individuals were not allocated to be surveyed at different intervals 'at random' and it is possible that those surveyed irregularly are at low risk of developing leprosy. It is also possible that individuals were more likely to have been present for a household survey if they had recently developed leprosy. If there were this kind of selective attendance at surveys there would be a bias to find higher incidence rates associated with shorter intervals between surveys. Alternatively it is possible that new cases of leprosy may have selectively avoided attending household surveys and this would have biased the results in the opposite direction. The possibility of such selective attendance or absence cannot 
be completely excluded but, in our view, the magnitude of such biases is likely to be small and a more plausible explanation of the findings is that the lower incidence rates measured in groups of individuals surveyed af ter longer intervals is due to the 'self-healing' of lesions.

This finding has implications both for the design of epidemiological studies of leprosy and also for the planning of control strategies. Frequent surveys done as a means of case detection will result in a large number of early cases being detected. A high proportion of these early cases probably do not require treatment and are likely to heal spontaneously if left untreated. Thus, frequent surveys may lead to the treatment of substantial numbers of early non-lepromatous leprosy cases which would otherwise regress spontaneously without treatment. Frequent surveys either of the general population or of contacts as a means of case detection are likely to be cost-ineffective and a survey once every 3-4 years (except for special purposes of examining trends etc) may be adequate.

Our findings also emphasize the importance of standardization for the between-survey gap, when the results of surveys with different survey gaps are compared. This may be especially important in vaccine trials in which the efficacy of a vaccine is assessed by a fall in the incidence rates. It is possible, for example, that the different results obtained in the BCG trials against leprosy in Uganda and Burma could be due, at least in part, to differences in the between-survey gaps in these 2 studies.

The follow-up examinations in the vaccinated and non-vaccinated groups in the BCG trial in Uganda were, on average, at $2 \frac{1}{2}$-year intervals..$^{6,7}$ These results showed that the incidence rate of leprosy was considerably lower in the vaccinated group than in the non-vaccinated group. In the WHO BCG trial in Burma $^{1-3}$ incidence rates were calculated in both vaccinated and non-vaccinated groups based on annual re-examinations. It has been noted ${ }^{1,4,5}$ that those in the vaccinated group had a higher incidence rate of leprosy in the first year of follow-up than those in the non-vaccinated group. Thus BCG may have precipitated the onset of clinical leprosy in individuals who were incubating the disease. ${ }^{13}$

It is possible that BCG may not prevent the development of clinical leprosy, but may enhance the healing of early leprosy lesions. Surveys done after an interval of 2-3 years would not detect cases that have developed and self-healed between surveys, whereas this effect would be much smaller if surveys were performed at annual intervals.

There has been alarm expressed in many parts of the world, where leprosy is endemic, that in spite of intensive leprosy control work, the incidence rates of leprosy remain high. A possible partial explanation of this is that intensive leprosy control results in the detection of an increased number of these early 'self-healing' cases. Thus standardization for the between-survey gap is essential for meaningf ul comparisons of estimates of incidence rates of leprosy and trends in the incidence rates of leprosy. 


\section{Acknowledgments}

We wish to express our thanks to Dr E P Fritschi and all the staff at the Schieffelin Leprosy Research and Training Centre who helped in this project, especially to Mr Kanagaraj, the team of paramedical workers and the staff of the Department of Epidemiology and Leprosy Control. Mr A D Askew and the Leprosy Mission International provided generous help and financial support. We thank Professor Muthukrishnan, Mr Srinivasan, Mr Kannan and Mr Gnanayaraj of the Indian Institute of Technology at Madras for assistance in data processing and analysis, Dr P E M Fine who helped in the planning and analysis of the study, Ross Institute and Tropical Epidemiology Unit staff, especially Mrs J Clarkson, Ms D Carson and $\mathrm{Mr} \mathrm{T}$ Marshall for help with the analysis of the data and $\mathrm{Mr}$ Christopher and Mr Lewis Kumar for secretarial help.

\section{References}

1 Bechelli LM, Gallego G, Uemura K, Engler V, Dominguey VM, Paredes L, Sundaresan T, Koch G, Matejka M. BCG vaccination of children against leprosy-Preliminary Report of WHO trial in Burma. Bull World Health Organization, 1970; 42: 235-81.

2 Bechelli LM, Gallego G, Gyi MM, Uemura K, Sundaresan T, Dominguey VM, Matejka M, Tamondeng C, Quagliato R, Engler V, Almann M. BCG vaccination of children against leprosy: seven-year findings of the controlled WHO trial in Burma. Bull World Health Organization, 1973; 48: 323-34.

${ }^{3}$ Bechelli LM, Kyaw Lwin, Gallego G, Gyi MM, Uemura K, Sundaresan T, Tamondeng C, Mukejka M, Sansarricq H, Walter J. BCG vaccination of children against leprosy: nine-year findings of the controlled WHO trial in Burma. Bull World Health Organization, 1974; 51: 93-9.

${ }^{4}$ Bechelli LM, Quagliato R. BCG and incidence of leprosy. Int J Lepr, 1953; 21: 586.

${ }^{5}$ Bechelli LM, Quagliato R. BCG and incidence of leprosy-a follow up study. Rev Bras Lepr, 1956; 24: 23-36.

${ }^{6}$ Brown JAK, Stone MM, Sutherland I. BCG vaccination of children against leprosy in Uganda: Results at end of second follow-up. Br Med J, 1968; 24-8.

7 Brown JAK, Stone MM, Sutherland I. Trial of BCG vaccination against leprosy in Uganda. Lepr Rev, 1969; 40: 3-7.

${ }^{8}$ Browne SG. Self-healing in leprosy. Report on 2749 patients. Lepr Rev, 1974; 45: 104-11.

9 Jesudasan K, Bradley D, Christian M. Spontaneous healing in a group of 88 unregistered patients with non-lepromatous leprosy (submitted for publication 1984).

${ }^{10}$ Lara CB, Nolasco JO. Self-healing, or abortive, and residual forms of childhood leprosy and their probable significance. Int J Lepr, 1956; 24: 245-63.

11 Noordeen SK. Infectivity of leprosy. In: Window on Leprosy. Chatterjee BR (ed), Gandhi Memorial Leprosy Foundation. 1978; 59-74.

12 Rao PSS, Karat ABA, Kaliaperumal VG. Incidence of leprosy in Gudiyatham Thaluk. Ind J Med Res, 1972; 60: 97-105.

13 Stoner GL, Belehu A, Nsibambi J, Warndorff J. Borderline tuberculoid leprosy following BCG vaccination-a case report. Int $J$ Lepr, 1981; 49: 16-20. 